\title{
Bacterial Etiology, Antibiotic Sensitivity Pattern and Risk Factors for Asymptomatic Bacteriuria during Pregnancy: Experience in a Tertiary Care Hospital
}

\author{
Khanum $\mathrm{S}^{\mathrm{a}^{*}}$, Ahmed $\mathrm{JU}^{\mathrm{b}^{*}}$, Khanam $\mathrm{K}^{\mathrm{c}}$
}

\begin{abstract}
Background: Urinary tract infections (UTIS) are common during pregnancy. Untreated asymptomatic bacteriuria (ASB) during pregnancy may cause serious complications including pyelonephritis and delivery of premature or low-birth-weight infants. This study aimed to assess the risk factors for asymptomatic bacteriuria, bacterial agents and their antibiotic susceptibility pattern in pregnant women attending in Combined Military Hospital (CMH), Dhaka.

Methods: This cross-sectional study was conducted in a total of 1540 pregnant women with no signs and symptoms of UTI from October 2013 to March 2015. Clean catch mid-stream urine samples were collected from all study participants using sterile containers. Urine samples were cultured using standard bacteriological methods. Identification of suspected colonies and antibiotic sensitivity testing were done. Patients having ASB were further evaluated to find out associated risk factors.

Results: Out of 1540 pregnant women, 254 (16.5\%) had asymptomatic bacteriuria (Colony forming unit $>10^{5} / \mathrm{mL}$ ). The most frequently isolated bacteria were Escherichia coli (E. coli) (50.4\%), followed by Klebsiella (24.0\%). The antibiotic sensitivity rate of bacterial isolates were highest for imipenem and amikacin. Among different associated conditions, anemia (16.5\%), gestational diabetes mellitus (GDM) (10\%) and past history of UTI (5.1\%) were found to be the most frequent factors associated with increased prevalence of ASB.

Conclusion: In this study, the prevalence of ASB was high among pregnant women with anemia, GDM and past history of UTI. E. coli was the most common organism causing ASB, which is less susceptible to conventional oral antibiotics but more susceptible to imipenem and amikacin. So, careful drug selection is required for successful outcome in ASB.
\end{abstract}

Keywords: Asymptomatic bacteriuria, pregnancy, urinary tract infection

(BIRDEM Med J 2016; 6(2): 79-83)

\section{Introduction}

Urinary tract infection (UTI) is a common health problem among women compared with men due to shorter urethra,

\section{Author Informations}

a. Major (Dr.) Shakila Khanum, FCPS (Obs \& Gyn), MCPS (Obs \& Gyn), Classified Specialist in Obstetrics \& Gynecology, Combined Military Hospital, Dhaka, Bangladesh

b. Dr. Jamal Uddin Ahmed, FCPS (Medicine), Assistant Professor of Medicine, BIRDEM General Hospital \& Ibrahim Medical College, Dhaka, Bangladesh

c. Colonel (Dr.) Khaleda Khanam, FCPS (Obs \& Gyn), Professor \& Head of the Department of Obstetrics \& Gynecology, Combined Military Hospital, Dhaka, Bangladesh

* Since both first two authors have equal contribution to the article, they both will be considered as first author of this article.

Address of correspondence: Major (Dr.) Shakila Khanum, Classified Specialist, Department of Obstetrics \& Gynecology, Combined Military Hospital, Dhaka, Bangladesh. E-mail: shakilashathi85@gmail.com

Received: July 19, 2015 closer proximity of the anus with vagina and pathogen entry facilitated by sexual activity. ${ }^{1,2}$ It is estimated that one in three women of childbearing age contracts UTI, which may manifest symptoms or remain asymptomatic. ${ }^{3}$ Pregnant women are more susceptible to UTI, owing to altered anatomical and physiological state during pregnancy. ${ }^{2}$

Asymptomatic bacteriuria (ASB) is a presence of a significant quantity of bacteria in a properly collected urine specimen from a person without symptoms or signs of UTI. ${ }^{4}$ Asymptomatic bacteriuria occurs in 2 to 7 percent of pregnant women. ${ }^{5,6}$ It typically occurs during early pregnancy, with only approximately a quarter of cases identified in the second and third trimesters. ${ }^{7}$ Factors that have been associated with a higher risk of bacteriuria include a history of prior UTI, pre-existing diabetes mellitus (DM), increased parity and low socioeconomic status. ${ }^{8,9}$ 
Incidence of ASB in pregnancy is very common in Bangladesh. ${ }^{10}$ Among the healthy pregnant mothers attending a tertiary care hospital in Dhaka, 30\% had asymptomatic bacteriuria. ${ }^{11}$ About $30 \%$ of women with untreated asymptomatic bacteriuria during pregnancy develop pyelonephritis, which may lead to delivery of premature or low-birth-weight infants. ${ }^{12}$ This risk is reduced by 70 to 80 percent if bacteriuria is eradicated. ${ }^{13}$ So, they must routinely be screened for and treated accordingly if ASB is found to be present. But it is not a common practice in Bangladesh and screening for ASB in pregnancy is not considered as an essential part of antenatal care (ANC) like routine checkup for albumin and sugar in urine. In some cases, it is generally done only in the first visit of ANC.

The bacteria with their sensitivity to various antimicrobial agents vary from place to place and in the same place from time to time. ${ }^{14}$ For appropriate treatment and to avoid over-treatment that would increase both costs and incidence of side effects, it is necessary to know the pathogens causing bacteriuria and their antibiotic sensitivity patterns. The aims of this study were to identify associated risk factors of asymptomatic bacteriuria in pregnancy and its etiological agents and their sensitivity pattern.

\section{Methods}

A cross-sectional study was conducted at Combined Military Hospital (CMH), Dhaka, Bangladesh from October 2013 to March 2015. The study population comprised of all pregnant women attending in the hospital for antenatal visit during the study period. However, pregnant women who were on antibiotic treatment two weeks prior to data collection and those with clinical signs and symptoms of UTI were excluded.

Demographic data including maternal age and gestational age were collected using questionnaires. Clean catch mid-stream urine samples were collected from all participants using wide-mouthed sterile capped container. The specimen was promptly transported to the microbiology laboratory and cultured within one hour of collection. Urinary routine examination and culture reports of all patients were analyzed. Those having ASB were further investigated to identify associated risk factors. Participation was fully voluntary and consent was obtained from all participants.

\section{Results}

A total 1540 apparently healthy pregnant women were screened. Single urine sample from each participant was collected and examined for ASB. Out of them, 254 (16.5\%) were found to have ASB. The mean age of the study participants was $26.13 \pm 6.37$ (15-49) years. The majority of the pregnant women were in their $1^{\text {st }}$ trimester $(16.8 \%)$ (Table-I). The rate of isolation was higher in the age group $>35$ years $(20.8 \%),(p=0.07)$. (Table- II).

Table I. Distribution of study population by trimester $(n=1540)$

\begin{tabular}{lccc} 
Trimester & $\begin{array}{c}\text { Total } \\
\text { number }\end{array}$ & $\begin{array}{c}\text { ASB } \\
\text { present }\end{array}$ & Percentage \\
\hline First & 980 & 165 & 16.8 \\
Second & 258 & 42 & 16.3 \\
Third & 302 & 47 & 15.6 \\
\hline
\end{tabular}

Table II. Distribution of study population by age group $(n=1540)$

\begin{tabular}{lccc} 
Age group & $\begin{array}{c}\text { Total } \\
\text { number }\end{array}$ & $\begin{array}{c}\text { ASB } \\
\text { present }\end{array}$ & Percentage \\
\hline $20-29$ & 920 & 162 & 17.6 \\
$30-35$ & 592 & 82 & 14.3 \\
$>35$ & 48 & 10 & 20.8 \\
\hline
\end{tabular}

Table III. Distribution of study population by Parity $(n=1540)$

\begin{tabular}{lccc} 
Parity & $\begin{array}{c}\text { Total } \\
\text { number }\end{array}$ & $\begin{array}{c}\text { ASB } \\
\text { present }\end{array}$ & Percentage \\
\hline Primi gravid & 960 & 160 & 16.7 \\
Multi-gravid & 580 & 94 & 16.2 \\
\hline
\end{tabular}

Table IV. Distribution of patients according to associated medical disorder: $(n=254)$

\begin{tabular}{lcc} 
Medical disorder & Total number & Percentage \\
\hline Anemia & 42 & 16.5 \\
Diabetes (GDM/DM) & 25 & 9.8 \\
Anemia and Diabetes & 18 & 7.0 \\
Past history of UTI & 13 & 5.1 \\
\hline
\end{tabular}


Of the bacterial isolates in urine culture, Escherichia coli was the commonest (50.4\%) organism, followed by Klebsiella (24.0\%). (Table-V). Other less frequently identified organisms were Enterobacter, Citrobacter and Candida albicans.

Antimicrobial sensitivity of isolated bacteria showed that most of the isolated organism were sensitive to imipenem and amikacin. Sensitivity to nitrofurantoin was moderate and to ciprofloxacin and penicillin was comparatively low. All of the isolated Staphylococcus aureus were sensitive to vancomycin. Pseudomonas was $20 \%$ resistant to imipenem and amikacin. (Table-VI)

Table V. Pattern of bacterial pathogens in urine culture $(n=254)$

\begin{tabular}{lcc} 
Organism & Total number & Percentage \\
\hline Escherichia coli & 128 & 50.4 \\
Klebsiella & 61 & 24.0 \\
Enterococcus spp. & 22 & 8.7 \\
Staphylococcus aureus & 19 & 7.5 \\
Pseudomonas aeruginosa & 10 & 3.9 \\
Other organisms & 14 & 5.5 \\
\hline
\end{tabular}

Table VI. Antibiotics Sensitivity Pattern of Bacterial isolates $(n=254)$

Name of Antibiotic

Antibiotic Sensitivity of organism, number (Percentage)

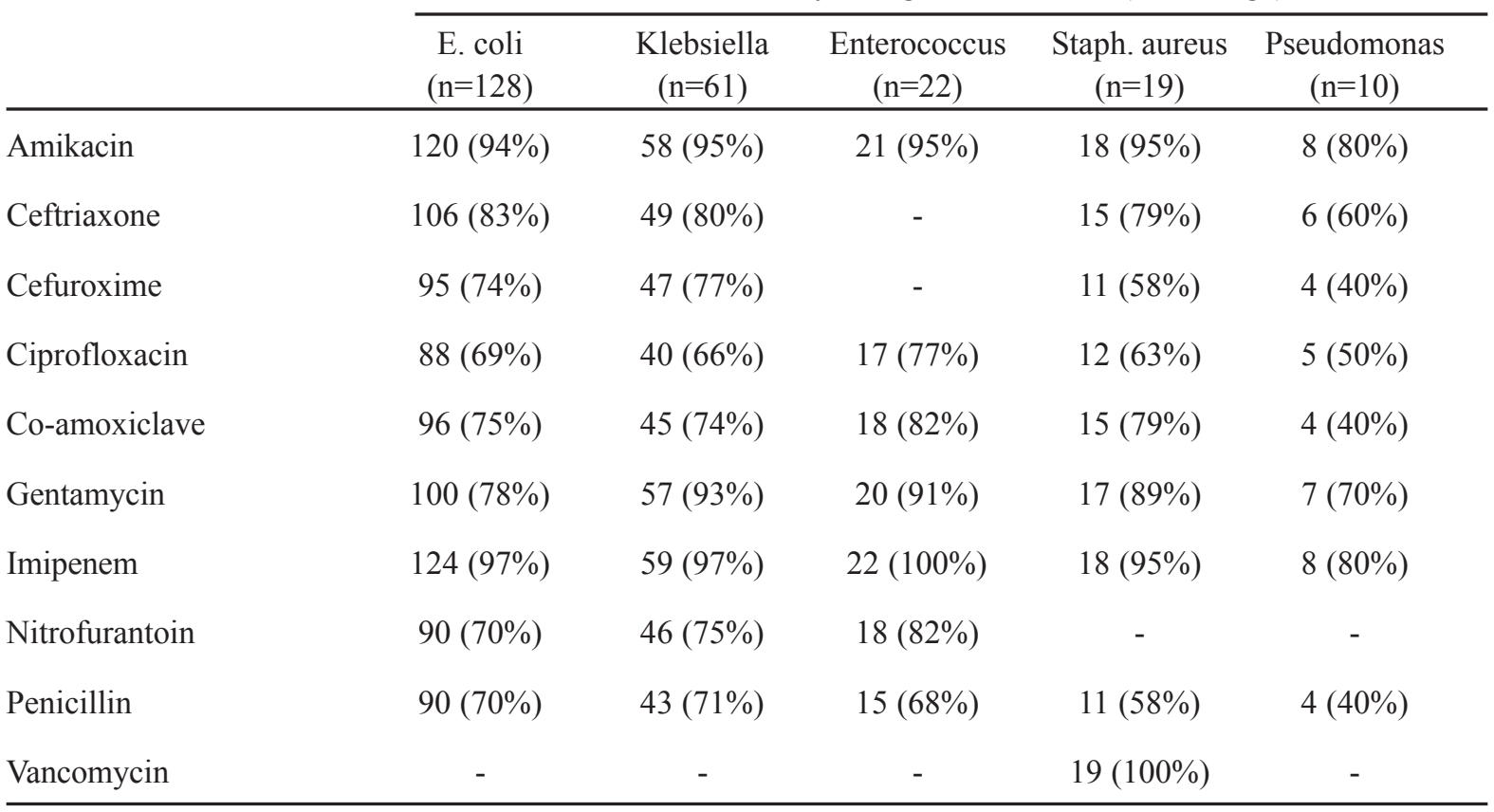

(Not all the samples were tested against all antibiotics) 


\section{Discussion}

Infections of the urinary tract are the most common bacterial infections encountered during pregnancy. These can be both symptomatic and asymptomatic. The prevalence of ASB was $18.9 \%$ in a study in Ethiopia. ${ }^{15}$ Another study in Tanzania found $13.0 \%$ prevalence of ASB. ${ }^{16}$ In a recent study in Bangladesh, the prevalence of ASB in a rural community was $12 \% .{ }^{10}$ In the current study, the prevalence of ASB among pregnant women attending Combined Military Hospital, Dhaka was $16.5 \%$, which is almost similar to other studies.

A number of conditions have been identified as risk factor for ASB, which include multiparity, gestational age, previous medical history of UTI, diabetes mellitus, anemia and anatomic urinary tract abnormalities. ${ }^{17,18}$ In this study maternal anemia, diabetes mellitus and previous history of UTI were found to be the associated risk factors for ASB among pregnant women. This is similar to other studies where anemia and glucose intolerance was significantly associated with ASB. ${ }^{18-20}$ This could be due to the lowering of systemic as well as local immunity due to diabetes, anemia and previous UTI. In this study there was no significant difference in the prevalence of ASB in respect of trimester, maternal age and parity. This was similar to many other studies. ${ }^{16,21,22}$

The predominant bacterial isolates observed in this study was E. coli (50.4\%). This is similar to most other studies throughout the world where $E$. coli has been consistently the predominant organism causing ASB. ${ }^{18,23,24}$ The major contributing factor for isolating higher rate of $E$. coli is due to urine stasis in pregnancy which favors for E. coli strain colonization. ${ }^{25,26}$ The second most common pathogen causing ASB in this study was Klebsiella, which is similar to another recent study. ${ }^{27}$

The sensitivity of imipenem and amikacin was high (80$100 \%$ ) to all organisms in this study, which is similar to other studies. ${ }^{14,27}$ Sensitivity to ceftriaxone and nitrofurantoin were moderate and to quinolone and penicillin were low, which is different from some other studies. ${ }^{15}$ No case of vancomycin resistant Staphylococcus aureus was seen in this study. One-fifth of the Pseudomonas were resistant to imipenem and amikacin.

\section{Conclusion}

The prevalence of ASB in pregnant women at $\mathrm{CMH}$, Dhaka was $16.5 \%$. Therefore, early screening of pregnant woman for presence of ASB and treating them according to antibiotic sensitivity pattern is utmost important to prevent maternal and fetal complications. E. coli and Klesiella were the most frequently found bacteria causing ASB and they are less sensitive to more commonly used antibiotics like penicillin, cephalosporins and quinolones, moderately sensitive to nitrofurantoin and highly sensitive to imipenem and amikacin. Since aminoglycosides and quinolones are contraindicated during pregnancy, so carbapenems and nitrofurantoin can be the drug of choice to treat ASB.

\section{Conflict of interest: None}

\section{References}

1. Feitosa DCA, Silva MG, Parada CMGL. Accuracy of simple urine tests for diagnosis of urinary tract infections in lowrisk pregnant women. Rev Latino-am Enfermagem 2009; 17(4):507-13.

2. Abdullah AA, Al-Moslih MI. Prevalence of asymptomatic bacteriuria in pregnant women in Sharjah, United Arab Emirates. East Mediterr Health J 2005; 11:5-6.

3. Duarte G, Marcolin AC, Quintana SM, Cavalli RC. Urinary tract infection in pregnancy. Rev Bras Ginecol Obstet 2008; 30:93-100.

4. Schnarr J, Smaill F. Asymptomatic bacteriuria and symptomatic urinary tract infections in pregnancy. Eur J Clin Invest 2008; 38(2):50-57.

5. Patterson TF, Andriole VT. Detection, significance, and therapy of bacteriuria in pregnancy. Update in the managed health care era. Infect Dis Clin North Am 1997; 11:593.

6. Nicolle LE, Bradley S, Colgan R. Infectious Diseases Society of America guidelines for the diagnosis and treatment of asymptomatic bacteriuria in adults. Clin Infect Dis 2005; 40:643.

7. Sobel JD, Kaye D. Urinary tract infections. In: Mandell GL, Bennett JE, Dolin R. (Eds). Bennett's Principles and practice of infectious diseases, Elsevier, Philadelphia; 2010: p.957.

8. Alvarez JR, Fechner AJ, Williams SF. Asymptomatic bacteriuria in pregestational diabetic pregnancies and the role of group B streptococcus. Am J Perinatol 2010; 27: 231.

9. Parveen K, Momen A, Begum AA, Begum M. Prevalence of urinary tract infection during pregnancy. J Dhaka National Med Coll Hos 2011; 17: 8-12.

10. Ullah MA, Barman A, Siddique MA, Haque AK. Prevalence of asymptomatic bacteriuria and its consequences in pregnancy in a rural community of Bangladesh. Bangladesh Med Res Counc Bull 2007; 33: 60-64.

11. Khatun AK, Rashid H, Chowdhury TA. Prevalence of urinary tract infection in pregnancy. J Bangladesh Coll. Phys Surg 1985; 2(2): 6-10.

12. Gilstrap LC, Leveno KJ, Cunningham FG, Whalley PJ, Roark ML. Renal infection and pregnancy outcome. Am J Obstet Gynecol 1981; 141: 709-16. 
13. Maclean $\mathrm{AB}$. Urinary tract infection in pregnancy. Brit $\mathrm{J}$ Urology 1997; 80(1): 10-13.

14. Tadesse A, Negash M, Ketema LS. Asymptomatic bacteriuria in pregnancy: assessment of prevalence, microbial agents and their antimicrobial sensitivity pattern in Gondar Teaching Hospital, North West Ethiopia. Ethiop Med J 2007; 45: 143-49.

15. Demilie T, Beyene G, Melaku S. Urinary bacterial profile and antibiotic susceptibility pattern among pregnant women in North West Ethiopia. Ethiop J Health Sci. 2012; 22: 121-28.

16. Masinde A, Gumodoha B, Kilonzo A, Mshana SE. Prevalence of urinary tract infection among women at Bugando Medical Center, Mwanza, Tanzania. Tanzania J Health Res 2009;11:154-59

17. Ramzan M, Bakhsh S, Salam A. Risk factors in urinary tract infection. Gomal J Med Sci 2004; 2: 50-53.

18. Enayat K, Fariba F, Bahram N. Asymptomatic bacteriuria among pregnant women referred to outpatient clinics in Sanandaj, Iran. Int Braz J Urol 2008; 34: 699-707.

19. Haider G, Zehra N, Afroze Munir A, Haider A. Risk factors of urinary tract infection in pregnancy. J Pak Med Assoc 2010; 60: 213-16.

20. Nandy P, Thakur AR, Ray CS. Characterization of bacterial strains isolated through microbial profiling of urine samples. On Line J Biol Sci 2007; 7: 44-51.
21. Hamdan HZ, Zaid AHM, Ali SK. Epidemiology of urinary tract infections and antibiotic sensitivity among pregnant women at Khartoum North Hospital. Ann Clin Microbiol Antimicrob 2011; 10: 1-5.

22. Turpin CA, Minkah B, Danso KA, Frimpong EH. Asymptomatic Bacteriuria in pregnant women attending antenatal clinic at Komfo Anokye teaching hospital, Kumasi, Ghana. Ghana Med J 2007; 41: 26-29.

23. Okonko IO, Ijandipe LA, Ilusanya OA. Incidence of urinary tract infection (UTI) among Pregnant women in Ibadan, South-Western Nigeria. Afr J Biotechnol 2009; 8: 6649-57.

24. Sescon NIC, Garingalao-Molina FD, Ycasiano CEJ, Saniel MC, Manalastas RM. Prevalence of Asymptomatic Bacteriuria and Associated Risk Factors in Pregnant Women. Phil J Microbiol Infect Dis 2003; 32: 63-69.

25. Imade PE, Izekor PE, Eghafona NO, Enabulele OI, Ophori E. Asymptomatic bacteriuria among pregnant women. North Am J Med Sci 2010;2: 263-66.

26. Moghadas AJ, Irajian G. Asymptomatic Urinary Tract Infection in Pregnant Women. Iranian J Pathol 2009; 4: 105-08.

27. Girishbabu RJ, Prakash R, Prashanth HV, Chandrashekar SC. Asymptomatic Bacteriuria in Patients with Diabetes Mellitus. National J Lab Med 2013;2(2):11-13. 